\title{
Hematuria Due to Leech Bite in the Urinary Bladder: A Case Report
}

\author{
BE-NAZIR AHMMAD ${ }^{1}$, SOHARAB UDDIN ${ }^{2}$, AHSANULLAH RUMI ${ }^{2}$
}

\begin{abstract}
Introduction:
Leeches phylum Annelida, class Hirudinea are blood sucking hermaphroditic parasite that attach themselves to vertebrate host, bite through skin and suck out a quantity of blood. ${ }^{1}$ They are common in Bangladesh especially in the southern districts like Barguna. Leech infestation primarily occurs in tropical areas, such as Mediterranean countries Africa and Asia $^{2}$. In infested water leech bite is hard to avoid. When lodged in the rectum, parasite can simulate the symptoms of gastrointestinal hemorrhage and while in the bladder as urological. They localize on the mucosa of the oropharynx, nasopharynx, tonsil, esophagus, or nose, but rarely in the rectal mucosa and in the bladder ${ }^{3-4}$. Leech bites do not hurt since they release an anesthetic when they sink their teeth (proboscis) into the skin but they do bleed profusely. Leeches use a heparin like anticoagulant when they bite to facilitate the flow of blood from the wound. Here we are reporting a case of leech endoparasitism in the bladder who had hematuria and retention of urine. We have used an early and innovative method to remove the parasite by bladder irrigation with hypertonic saline.
\end{abstract}

\section{Case Report:}

A 10 yr old boy admitted at Barguna General Hospital presented with hematuria followed by retention of urine for 20-24 hrs. and their was history of a leech entered per urethra at the same time. He had no history of fever, perineal trauma and no history of consanguinity or family history of bleeding disorders. He felt lower abdominal discomfort and difficulty in micturate. With an effort of changing body posture and movement he could micturate with a small volume of urine mixed with blood. At the emergency dept. catheterization had been done to relieve pain and discomfort and to pass urine. Hematuria was profuse and the boy admitted in the ward, where an intravenous channel was established and infused normal saline, at the moment vitals were found abnormal. BP was 80/50 $\mathrm{mm}$ of $\mathrm{Hg}$, pulse was $110 / \mathrm{min}$, with cold skin and the

1. Junior Consultant (Child), Barguna General Hospital, Barguna 2. Medical Officer, Barguna General Hospital, Barguna Correspondence: Dr. Be-Nazir Ahmmad, Junior Consultant (Child), Barguna General Hospital, Barguna, Mobile: 01720038608, E-mail: benazir.ahmmad@gmail.com boys sweating. The boy was stabilized with volume replacement. He was pale anicteric, temperature was normal, there was no lymphadenopathy or hepatosplenomegaly and no obvious bleeding sites, bony tenderness, joint swelling or arthritis. Haemogram was normal except haemoglobin was $9 \mathrm{gm} / \mathrm{dl}$. Liver and renal function test, coagulation profiles were normal. The leech was not spontaneously removed within 2 days while hematuria continued. After removal of catheter there was again retention and difficulty in micturation as the leech became a nodular lump which blocked the internal urethral opening. As there was no cystoscopic facilities, reintroduction of the Foly's catheter was done and we irrigated hypertonic saline $(3 \% \mathrm{NaCl})$ for 30 min and catheter was removed. A $5.6 \mathrm{~cm}$ length black leech characters resemble an aquatic leech (family hirudinidae) with eroded body passed per urethra within $1 / 2$ an hour. Due to an effect of hypertonic saline the leech was anesthetized, shrinked and eroded or destructed and easily passed while attempted to micturate. We attempted to control oozing/bleeding by giving local and systemic tranexaemic acid. Hematuria continued for the next 10-12 hrs. then stopped. The patient recovered promptly and was discharged on the next day. A long term follow-up was not possible due to local circumstances. Here we added a broad spectrum antibiotic to prevent infection.

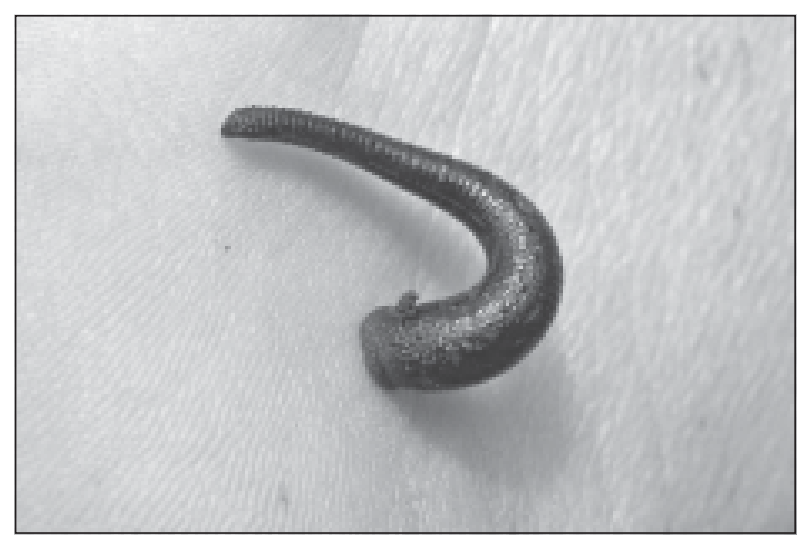

Fig.-1: Leech

\section{Discussion:}

Leeches may be divided into two classes aquatic and land. Land leeches have powerful jaws that can penetrate the skin so that they can attach anywhere 
on the external surface of the body. Aquatic leeches have weak jaws and require soft tissues, such as the mucosa of upper aerodigestive tracts to feed on; they have a worldwide distribution 7 . Aquatic types are acquired while bathing, fishing, working or drinking unfiltered water or swimming in contaminated ponds or pools. Due to these mode of transmission almost all cases have been reported from less-developed countries in the rural areas or distant urban areas where use of safe water is often a problem ${ }^{8}$. When attached to the mucous membrane, they ingest blood averaging 10 times of their weight ${ }^{9}$. In this regard aquatic leeches are more dangerous than land leeches because they are more likely to cause severe anemia which may require blood transfusion ${ }^{1}$. Cundall et al ${ }^{10}$ reported three patients with severe anemia, one of whom died. Our patient had suffered from haematuria lower abdominal pain and distention. Pain was due to retention of urine for several hours. He required no blood transfusion.

The most common mode of penetration in leech endoparasistism is nasal infestation ${ }^{11}$. In the stomach, the leech is usually destroyed by gastric acid ${ }^{7}$. Therefore it has not been described in the lower intestines, although it can pass from outside through the anal sphincter into the rectum ${ }^{12}$. The presence of a leech in the rectum has been reported in a limited number; only 2-3 cases $^{12,14}$. Cases of leech incduced bleeding from bladder is also uncommon and seldom reported $^{13}$. To the best of our knowledge this is the first case report in Bangladesh regarding leech bite. The possibilities of leech endoparasitism should not be overlooked in patients (especially in children) presenting with epistaxis, rectal bleeding, hemoptysis or hematuria and a recent history of contact with fresh water lakes or streams in areas where aquatic leeches are commonly found ${ }^{9,11,12}$. Diagnosis is not easier when the leech is in the bladder unless the patient recognised it while on entrance. After exclusion of all kinds of bleeding disorders and hematuria where facilities are available ultrasonography and direct cystoscopic examination needed for confirmation. Leech bites are painless and result in a triradiate wound that remain open for a long time and heals slowly ${ }^{15}$. As was in our case, the commonest complication of leech bite is blood oozing. The amount and duration of bleeding vary according to the area bitten, with bleeding from the vagina, rectum, urinary bladder and pharynx having been reported ${ }^{12,15}$. Faust et al. ${ }^{16}$ reported that prolonged hemorrhage might result in anemia and death. The mean duration of bleeding from a leech bite wound was reported as $10 \mathrm{hrs}$ in one study (range 6.5-23). In our patient bleeding was continued for about 36 hrs and then persisted intermittingly for the next 6 hours after removal inspite of application of tranexaemic acid both local and systemic. However he did not have any hematological problem. After the leech was removed, the amount of oozing blood was not excessive, so no other method (eg. cystoscopic electrocoagulation) was needed to stop it completely. Hemostatic drug was sufficient to control the oozing in this case.

Since a leech attaches strongly with its suckers and has a soft and slippery body surface that ruptures easily, it is difficult to hold and remove a leech with force $^{17}$. As in our case, the boy could not resist entrance of the leech and after hypertonic saline (3\% $\mathrm{NaCl}$ ) irrigation (more suitable in older children) shrinking and rupturing the leech as well as paralyses it. Afterwards, it could be removed cystoscopically or by natural voiding. In our case it was passed through voiding.

\section{Conclusion:}

Leech bite in urinary bladder associated with profuse hematuria is an uncommon complication that can be managed simply by bladder irrigation with $3 \% \mathrm{NaCl}$ solution followed by cystoscopic removal or at times by spontaneous voiding. Leech infestation should be considered as a cause of hematuria in endemic areas, otherwise the diagnosis will be missed. We should be cautious enough to prevent leech bite while doing job in the leech contaminated/infested water.

\section{References:}

1. El-Awad ME, Patil K. Hematemesis due to leeck infestation. Ann Trop Paediatric 1999; 10: 61-2.

2. Uygur K, Yasan H, Yavuz L, Dorgu H. Removal of a laryngeal leech: A safe and effective method. Am J Otolaryngol 2003; 24: 338-40.

3. Bilgen C, Karci B, Uluoz, U. A nasopharyngeal mass: leech in the nasopharynx. Int. J Pediatr Otorhinolaryngol 2002; 64: 73-6.

4. Kaygusuz I, Yalcin S, Keles E. Leeches in the larynx. Eur Arch Otorhinolaryngol 2001; 258: 455-7.

5. Mohammad Y, Rostum M, Dubaybo BA. Laryngeal hirudiniasis: an unusual Cause of airway obstruction and hemoptysis. Pediatr Pulmonol 2002; 33: 224-6. 
6. White GB, Leeches and leech infestation. In: Cook GC, editor. Manson's tropical diseases. London: Saunders 1998; 20: 1523-5.

7. Solomon E. Leech-an unusual cause of (Laryngotracheal) obstruction. Ethiop Med J 1991; 29: 141-2.

8. al-Hadrani A, Debry C, Faucaon F, Fingerhut A. Hoarseness due to leech ingestion. J Laryngol Otol 2000; 114: 145-6.

9. Cundall DB, Whitehead SM, Hechtel FO. Severe anemia and death due to the pharyngeal leech Myxobdella africana. Trans R Soc Trop Med Hyg 1986; 80: 940-4.

10. Bergua A, Vizmanos F, Monjon FJ, Blasco RM. Unavoidable epistaxis in the nasal infestation of leeches. Acta Otor-rinolaringol Esp 1993; 44: 391-3.
11. Raj SM, Radzi M, Tee MH. Severe rectal bleeding due to leech bite. Am J Gastroenterol 2000; 95: 1607.

12. Deka PM, Rajeev TP. Unusual cause of hematuria. Urol Int 2001; 66: 41-2.

13. Behcet AL, Mehmet EY, Mustafa ALDEMIR. Rectal Bleeding due to leech bite : a case report. Turkish Journal of Trauma and Emergency Surgery 2011; 17(1) : 83-86.

14. Pandey CK, Sharma R, Baronia A, Agarwal A, Singh N. An unusual cause of respiratory distress: Live leech in the larynx. Anesth Analg 2000; 90: 1227-8.

15. Faust EC, Russel PF, Jurg RC. Craig and Faust's clinical parasistology. Philadelphia: Lea and Febiger 1970; 8: 563-70.

16. Litch JA, Bishop RA. Saturated aqueous sodium chloride solution for the removal of leeches. Trop Doct 2000; 30: 102. 